Article

\title{
Antioxidant Assessment of Prenylated Stilbenoid-Rich Extracts from Elicited Hairy Root Cultures of Three Cultivars of Peanut (Arachis hypogaea)
}

\author{
Gaurav Gajurel ${ }^{1,2}\left[\right.$, Rokib Hasan ${ }^{1,2} \mathbb{1}$ and Fabricio Medina-Bolivar $1,3, * \mathbb{C}$ \\ 1 Arkansas Biosciences Institute, Arkansas State University, Jonesboro, AR 72467, USA; \\ gaurav.gajurel@smail.astate.edu (G.G.); mdrokib.hasan@smail.astate.edu (R.H.) \\ 2 Molecular Biosciences Graduate Program, Arkansas State University, Jonesboro, AR 72467, USA \\ 3 Department of Biological Sciences, Arkansas State University, Jonesboro, AR 72467, USA \\ * Correspondence: fmedinabolivar@astate.edu; Tel.: +1-8706804319
}

Citation: Gajurel, G.; Hasan, R.; Medina-Bolivar, F. Antioxidant Assessment of Prenylated Stilbenoid-Rich Extracts from Elicited Hairy Root Cultures of Three Cultivars of Peanut (Arachis hypogaea) Molecules 2021, 26, 6778. https:// doi.org/10.3390/molecules26226778

Academic Editor: Andrea Ragusa

Received: 28 October 2021

Accepted: 7 November 2021

Published: 10 November 2021

Publisher's Note: MDPI stays neutral with regard to jurisdictional claims in published maps and institutional affiliations.

Copyright: (c) 2021 by the authors. Licensee MDPI, Basel, Switzerland. This article is an open access article distributed under the terms and conditions of the Creative Commons Attribution (CC BY) license (https:// creativecommons.org/licenses/by/ $4.0 /)$.

\begin{abstract}
Peanut produces prenylated stilbenoids upon biotic stress. However, the role of these compounds against oxidative stress have not been thoroughly elucidated. To this end, the antioxidant capacity of extracts enriched in prenylated stilbenoids and derivatives was studied. To produce these extracts, hairy root cultures of peanut cultivars Hull, Tifrunner, and Georgia Green were co-treated with methyl jasmonate, cyclodextrin, hydrogen peroxide, and magnesium chloride and then the stilbenoids were extracted from the culture medium. Among the three cultivars, higher levels of the stilbenoid derivatives arachidin- 1 and arachidin- 6 were detected in cultivar Tifrunner. Upon reaction with 2,2-diphenyl-1picrylhydrazyl, extracts from cultivar Tifrunner showed the highest antioxidant capacity with an $\mathrm{IC}_{50}$ of $6.004 \mu \mathrm{g} / \mathrm{mL}$. Furthermore, these extracts had significantly higher antioxidant capacity at $6.25 \mu \mathrm{g} / \mathrm{mL}$ and $3.125 \mu \mathrm{g} / \mathrm{mL}$ when compared to extracts from cultivars Hull and Georgia Green. The stilbenoid-rich extracts from peanut hairy roots show high antioxidant capacity and merit further study as potential nutraceuticals to promote human health.
\end{abstract}

Keywords: stilbenoid-rich extract; prenylated stilbenoids; arachidin; peanut; antioxidant; elicitation; hairy root

\section{Introduction}

Reactive oxygen species (ROS) are continually produced by living organisms during cellular metabolism. At physiological concentration, ROS may be required for the normal function of the cell. However, excess accumulation of ROS can cause oxidative stress, damaging the cellular macromolecules like DNA, lipids, and proteins, and eventually lead to disease conditions. In humans, the harmful effect of ROS has been associated with the occurrence of more than 100 diseases, including neurodegenerative disease, heart-related disease, diabetes, and cancer [1-3]. Antioxidants protect the living system from the harmful effect of ROS by scavenging them directly or indirectly [4]. In the past few years, plantderived stilbenoids and their derivatives have gained considerable interest as a source of antioxidants due to their diverse chemical structure and biological activities with potential application as pharmacological agents [5].

Stilbenoids are a group of polyphenolic compounds that can be found in a limited number of plant families, including those of grapevine (Vitaceae), peanut (Fabaceae), and blueberry (Ericaceae). These compounds are phytoalexins that are produced upon infection by fungus and other pathogens to protect the host plant against them. Thus, the peanut plant produces stilbenoids as a defense response to biotic stress and more than 45 stilbenoids and their derivatives have been reported in peanut tissues subjected to biotic stresses [6-10]. The first described peanut stilbenoids include resveratrol and the prenylated stilbenoids arachidin-1, arachidin-3, and isopentadienyl trihydroxystilbene [11]. 
Among these stilbenoids, the most studied is resveratrol due to its biological properties beneficial to human health including antioxidant, cardioprotective, anticancer, antiaging, and others. Despite the wide range of bioactivities of resveratrol, this stilbenoid has shown limited bioavailability in vivo due to its rapid metabolism into glucuronide and sulfate metabolites [12]. Interestingly, natural resveratrol analogs such as the prenylated stilbenoids may have increased bioavailability due to favorable metabolic profiles as demonstrated by in vitro assays [13]. Additionally, prenylated stilbenoids have shown to exhibit enhanced or equivalent antioxidant, anti-inflammatory, and anti-adipogenic activities when compared to resveratrol [14-16].

Hairy root cultures of peanut cv. Hull was established previously using Agrobacterium rhizogenes to enhance the production of non-prenylated and prenylated stilbenoids [17]. The hairy roots when treated with a combination of methyl jasmonate (MeJA), cyclodextrin (CD), hydrogen peroxide, and magnesium chloride secrete several stilbenoids and their derivatives into the culture medium and thus these compounds can be extracted from the culture medium [18]. This stilbenoid-rich extract from peanut hairy root culture medium is rich in the non-prenylated stilbenoid resveratrol and prenylated stilbenoids arachidin-5, arachidin-1, arachidin-2, arachidin-3, and others with diverse biological activity (Figure 1). Similarly, treatment of hairy roots from peanut cv. Kalasin 2 with chitosan, MeJA, and CD induced a large amount of arachidin- 1 and arachidin-3 [19]. However, a study comparing the biological properties of stilbenoid-rich extracts from hairy roots of different peanut cultivars have not been done thoroughly.<smiles>Oc1ccc(C=Cc2cc(O)cc(O)c2)cc1</smiles>

resveratrol<smiles>CC1(C)C=Cc2c(O)cc(/C=C/c3ccc(O)c(O)c3)cc2O1</smiles>

arachidin-6<smiles>CC(C)=CCc1c(O)cc(C=Cc2ccc(O)cc2)cc1O</smiles>

arachidin-2<smiles>CC(C)/C=C/c1c(O)cc(/C=C/c2ccc(O)cc2)cc1O</smiles>

arachidin-3<smiles>CC(C)=CCc1c(O)cc(C=Cc2ccc(O)c(O)c2)cc1O</smiles>

arachidin-5<smiles>CC(C)/C=C/c1cc(/C=C/c2ccc(O)c(O)c2)cc(O)c1O</smiles>

arachidin-1

Figure 1. Chemical structure of six main stilbenoids found in elicited peanut hairy root culture. All compounds are shown in their trans-isomer.

In this study, we compared the antioxidant property as determined by DPPH (2,2-diphenyl-1-picrylhydrazyl) assay of stilbenoid-rich extracts obtained from elicited peanut hairy root cultures of three cultivars, i.e., Tifrunner, Hull, and Georgia Green. In addition, a comparative study of the yield of stilbenoids and their derivatives in these three cultivars of peanut was performed. We established a hairy root line from the whole-genome sequenced peanut cv. Tifrunner, and reported the production of prenylated stilbenoids and the ring-prenylated piceatannol derivative arachidin-6 in this cultivar for the first time.

\section{Results and Discussion}

\subsection{Development and Characterization of Peanut cv. Tifrunner Hairy Roots}

The peanut hairy root platform provides a potential platform for the bioproduction of prenylated stilbenoids and elucidation of new genes involved in the biosynthetic pathway of these compounds [11]. Recently, the whole genome of peanut cv. Tifrunner has been sequenced providing the potential to discover candidate genes of interest in this economically important crop [20]. Thus, the hairy root system of the whole genome sequence cultivar would provide valuable information to further elucidate the biosynthetic pathway 
for prenylated stilbenoids. In present work, hairy root culture of peanut cv. Tifrunner was established and treated with the combination of elicitors for stilbenoid profiling. Additionally, the antioxidant properties of the stilbenoid-rich extract from elicited hairy roots from three cultivars were compared for their potential application as nutraceuticals to promote human health.

Several hairy root lines of peanut $\mathrm{cv}$. Tifrunner were produced by infecting leaves from 4-week-old seedlings with A. rhizogenes ATCC 15834. The wounded leaves were cultured and subcultured on MSV medium with antibiotics for 3 to 5 weeks until the development of hairy roots to avoid overgrowth of Agrobacterium. Tifrunner hairy root line 1 (Figure 2) was selected based on its sustained growth in liquid culture. PCR analysis of line 1 was performed for confirming the presence of $a u x 1$ and rolC genes, indicating the integration of the two T-DNA, $\mathrm{T}_{\mathrm{L}}$-DNA, and $\mathrm{T}_{\mathrm{R}}$-DNA, from Ri plasmid of A. rhizogenes ATCC 15834 into the plant genome. Furthermore, PCR amplification of the virD2 gene was negative suggesting the absence of any Agrobacterium in the root tissue (Supplementary Materials Figure S1).

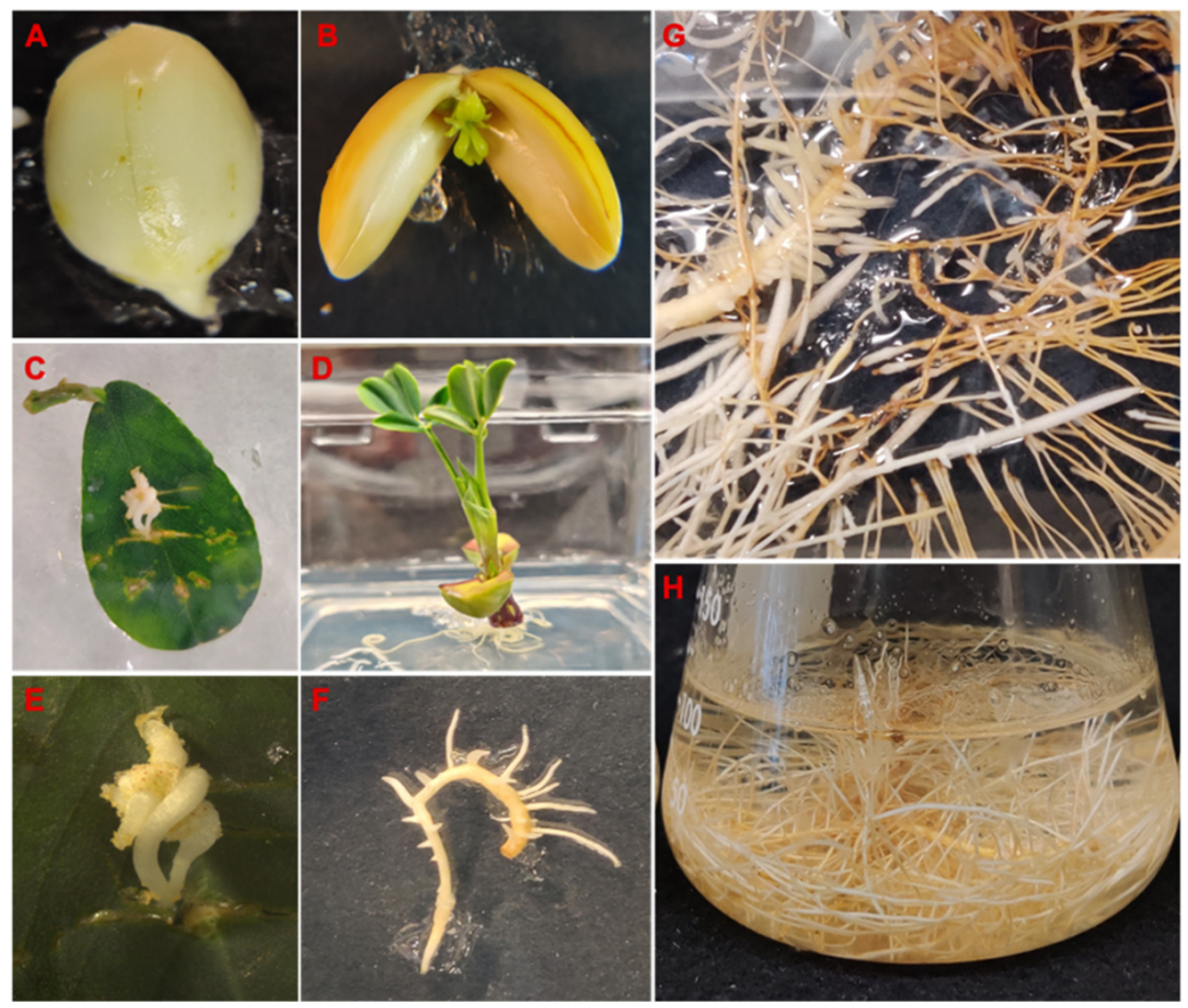

Figure 2. Germination and establishment of hairy root cultures of peanut cv. Tifrunner. (A): Seed germination; (B): One-week-old seedling; (D): Three-week-old seedling; (C,E): Hairy root development from leaf infected with Agrobacterium rhizogenes; (F): Branching of hairy roots after excision from the leaf; (G): Phenotype of hairy root line 1 on semi-solid medium; $(\mathbf{H})$ : Phenotype hairy root line 1 in liquid medium after 15 days in culture.

\subsection{Production of Prenylated Stilbenoids in Hairy Roots of Peanut cos. Tifrunner, Hull, and Georgia Green}

The hairy root cultures of peanut cvs. Tifrunner, Hull, and Georgia Green were elicited as described before for comparison of their stilbenoid profile and yields. Notably, the color of the medium changed from clear to yellow in the hairy root cultures of all three cultivars suggesting the secretion of stilbenoids in the culture medium after elicitation treatment 
(Figure 3) [17]. The stilbenoid content in the culture medium after $168 \mathrm{~h}$ elicitation treatment was analyzed using HPLC (Figure 4). Accordingly, all three hairy roots were able to secrete resveratrol and different prenylated stilbenoids like arachidin-5, arachidin-1, arachidin-2, and arachidin- 3 into the medium upon elicitation. The production of these stilbenoids suggests that the stilbenoid-specific prenyltransferase responsible for their biosynthesis might be expressed in these three cultivars of peanuts [11].

Before elicitor treatmen

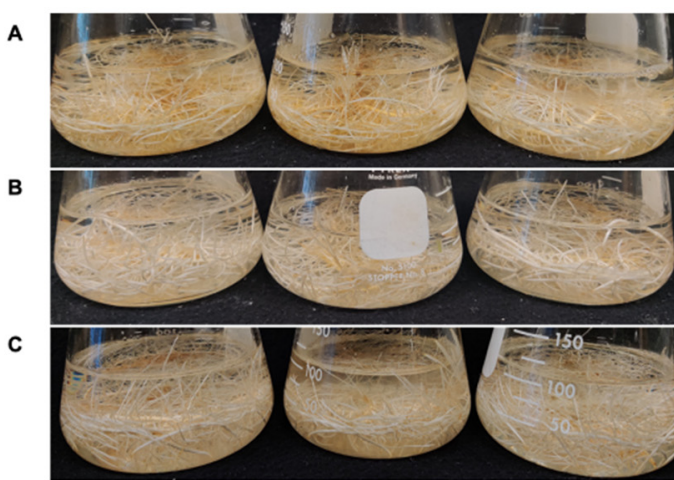

After elicitor treatment

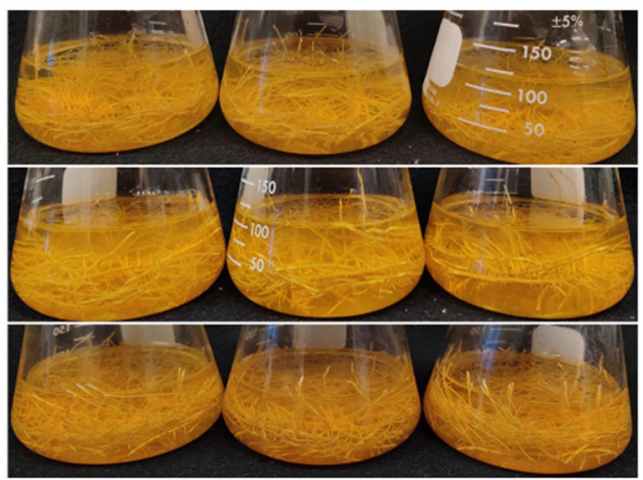

Figure 3. Elicitation of hairy root cultures. Changes in the phenotype of (A): Peanut cv. Tifrunner hairy root line 1; (B): Peanut cv. Hull line 3; (C): Peanut cv. Georgia Green after $168 \mathrm{~h}$ of treatment with different elicitors: $125 \mu \mathrm{M}$ methyl jasmonate (MeJA), $18 \mathrm{~g} / \mathrm{L}$ cyclodextrin (CD), 3 mM hydrogen peroxide $\left(\mathrm{H}_{2} \mathrm{O}_{2}\right)$ and $1 \mathrm{mM}$ magnesium chloride $\left(\mathrm{MgCl}_{2}\right)$ in a $100 \mathrm{~mL}$ elicitation medium.
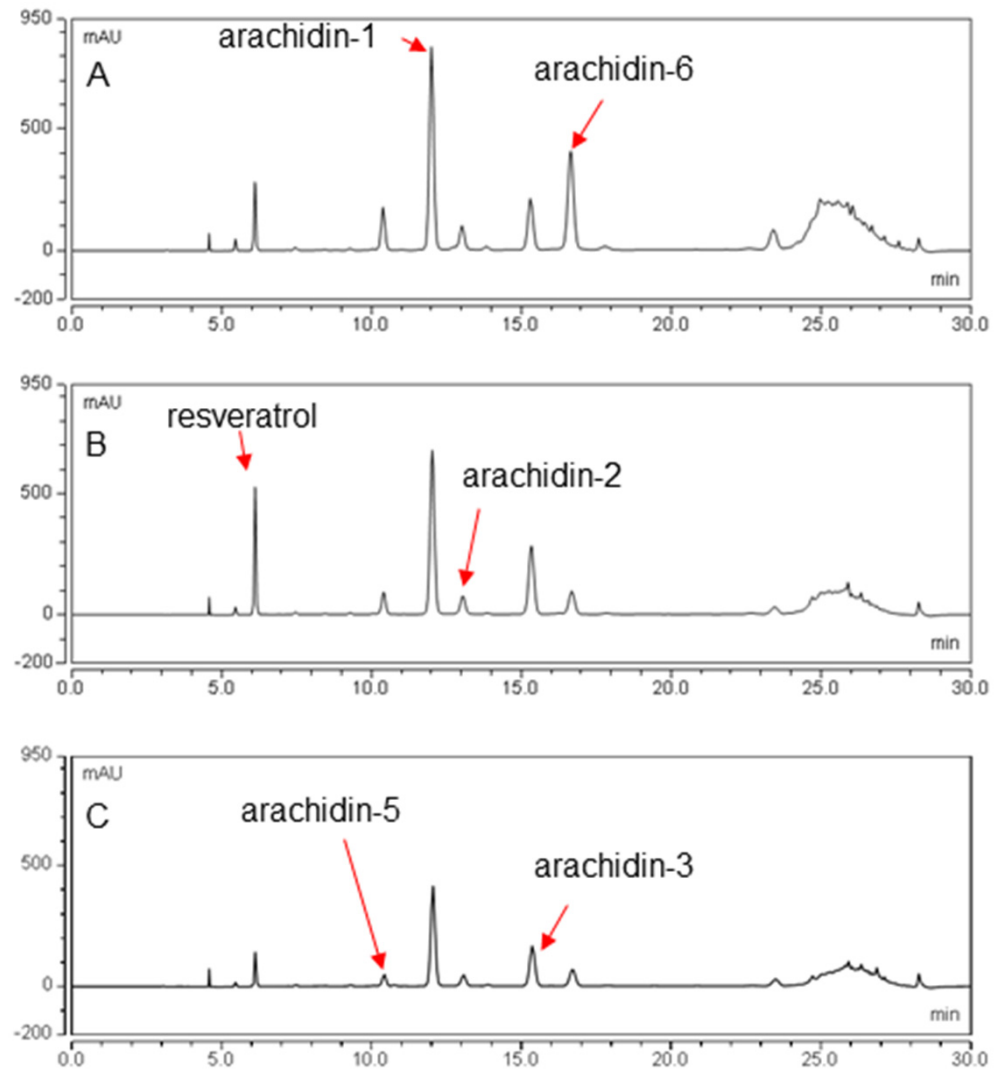

Figure 4. Comparison of secreted stilbenoid profiles among three different cultivars of peanut hairy root cultures. HPLC chromatograms of culture medium extract of hairy root cultures of (A): Peanut cv. Tifrunner; (B): Peanut cv. Hull line 3; (C): Peanut cv. Georgia Green after 168 h elicitor treatment. All chromatograms were monitored at $340 \mathrm{~nm}$. 
The yield of arachidin-5, arachidin-1, and arachidin-2 was higher in the medium of the Tifrunner hairy root culture when compared to the other two cultivars. Interestingly, the yield of resveratrol and arachidin-3 was higher in cultivar Hull (Figure 5). The yield of arachidin-5 in cv. Tifrunner was $24.07 \pm 4.33 \mathrm{mg} / \mathrm{L}$ which was approximately 2.2- and 4.7-fold higher than in Hull and Georgia Green hairy roots, respectively. Similarly, the yield of arachidin-1 in cv. Tifrunner was $169.73 \pm 25.17 \mathrm{mg} / \mathrm{L}$ which was significantly higher than in Hull and Georgia Green, respectively. The yield of arachidin-2 in cv. Tifrunner was $31.75 \pm 5.59 \mathrm{mg} / \mathrm{L}$ which was approximately 1.4- and 2.3-fold higher than in Hull and Georgia Green, respectively. The yield of resveratrol in cv. Hull was $44.1 \pm 3.3 \mathrm{mg} / \mathrm{L}$ which was significantly higher than Tifrunner and Georgia Green hairy roots, respectively. Whereas the yield of arachidin-3 in cv. Hull was $52.24 \pm 3.66 \mathrm{mg} / \mathrm{L}$ which was approximately 1.2- and 1.7-fold higher than in Tifrunner and Georgia Green hairy root respectively (Figure 5).

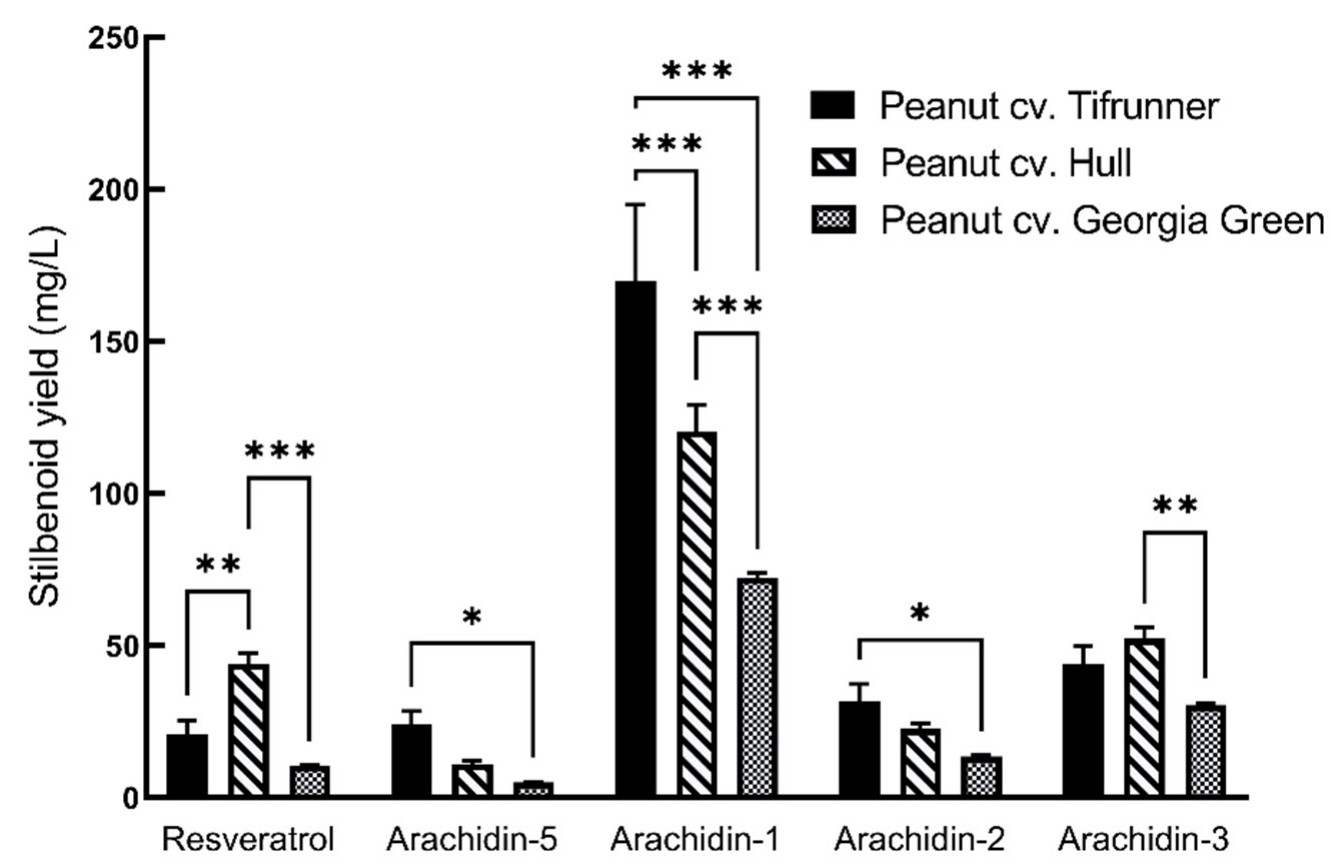

Figure 5. Comparison of stilbenoid yield in hairy root cultures of peanut cultivars Tifrunner, Hull (line 3), and Georgia Green. Yield is expressed in $\mathrm{mg} / \mathrm{L}$ and each bar represents the average of three technical replicates of stilbenoids extracted from $0.9 \mathrm{~L}$ elicited medium. Error bars represent standard deviation. Statistical analysis was performed with two-way ANOVA with Tukey's multiplecomparisons test. The asterisks above the connecting line represent a significant difference when compared to the stilbenoid yield among the three cultivars $\left({ }^{*}, p<0.033 ;{ }^{* *}, p<0.002 ;{ }^{* * *}, p<0.001\right)$.

Particularly in the Tifrunner cultivar, arachidin- 1 and arachidin- 6 were the predominant stilbenoids when compared to the Georgia Green and Hull cultivars. We identified arachidin- 6 in the ethyl acetate extract of the culture medium by comparing characteristic UV spectrum $\left(\lambda_{\max }\right)$, and mass spectrometric analysis of arachidin-6 from Rhizopus-elicited peanut seedlings [21] (Supplementary Materials Figures S3-S5). A total of $5.3 \mathrm{mg}$ of arachidin-6 $\left(\lambda_{\max }=344 \mathrm{~nm}\right)$, was purified from the peanut $\mathrm{cv}$. Tifrunner hairy root culture medium using semi-preparative HPLC method (Supplementary Materials Figure S2). As shown in Table 1, the precursor ion of the isolated compound $\left([\mathrm{M}-\mathrm{H}]^{-}, m / z 309\right)$ provided the main fragment with a $[\mathrm{M}-\mathrm{H}]^{-}$of $m / z 265$ in $\mathrm{MS}^{2}$ which suggested that the purified compound was arachidin- 6 as described in fungal-challenged peanut. Interestingly, arachidin-6 has been reported to show moderate antimicrobial activity against methicillin-resistant Staphylococcus aureus with a minimum inhibitory concentration ranging from 50 to $75 \mu \mathrm{g} / \mathrm{mL}$ [21]. The difference in yield of stilbenoids suggests that the 
enzymes responsible for the production of these compounds are expressed at different levels among the hairy roots from different cultivars. To our knowledge, this is the first study to show the production of stilbenoids in peanut $\mathrm{cv}$. Tifrunner.

Table 1. Tandem mass spectrometry analysis of arachidin- 6 detected in ethyl acetate extract from the medium of elicited peanut cv. Tifrunner hairy root culture. Analysis was done by HPLC-PDA-electronspray ionization-MS ${ }^{3}$.

\begin{tabular}{|c|c|c|c|c|c|c|c|}
\hline$t_{\mathrm{R}}(\mathrm{Min})$ & $\begin{array}{c}\text { UV Max } \\
(\mathrm{nm})\end{array}$ & {$[\mathbf{M}-\mathbf{H}]^{-}$} & MS $^{2}$ Ions $^{a}$ & MS $^{3}$ Ions & {$[\mathbf{M}+\mathbf{H}]^{+}$} & $\mathrm{MS}^{2}$ Ions $^{\mathrm{a}}$ & MS $^{3}$ Ions \\
\hline 16.57 & 344 & 309 & 291, 265, 294 & 159,249 & 311 & $201,283,296$ & $159,173,183$ \\
\hline
\end{tabular}

The first stilbenoidspecific prenyltransferases, AhR4DT- 1 and AhR3'DT-1, involved in the prenylation of stilbenoids have been identified from peanut. Specifically, AhR4DT1 catalyzes the transfer of a 3,3-dimethylallyl group to the C-4 carbon of the A-ring of resveratrol and piceatannol, producing arachidin- 2 and arachidin-5, respectively. AhR3'DT1 can use resveratrol as substrate to add a 3,3-dimethylallyl group to the $\mathrm{C}-3^{\prime}$ of the $\mathrm{B}$ ring. However, the biosynthetic steps for the production of arachidin- 1 and arachidin-3 have not been elucidated yet [11]. The Tifrunner hairy root line might provide a platform to further elucidate the biosynthetic pathway for prenylated stilbenoids and their derivatives in peanut.

\subsection{Comparison of Antioxidant Activity of Stilbenoid-Rich Extract from Hairy Roots of Three Peanut Cultivars}

The antioxidant activities of the extract obtained from the culture medium of elicited hairy roots of peanut cvs. Tifrunner, Hull, and Georgia Green were compared using the scavenging effect of DPPH. DPPH scavenging assay is economic, reliable, efficient, and sensitive method for measuring the antioxidant activity of non-enzymatic antioxidants such as stilbenoids [2,22]. After incubation of DPPH solution with a stilbenoid-rich extract from different cultivars for $30 \mathrm{~min}$, the violet color of DPPH changed to yellow confirming reduction of DPPH for all extract concentrations above $1.5625 \mu \mathrm{g} / \mathrm{mL}$.

Interestingly, the stilbenoid-rich extract of peanut cv. Tifrunner had a higher scavenging effect on DPPH radical when compared to the stilbenoid-rich extract of peanut cvs. Hull and Georgia Green at all concentrations. The DPPH scavenging rate for the stilbenoid-rich extract from all three extracts was highest at the extract concentration of $100 \mu \mathrm{g} / \mathrm{mL}$ and the scavenging rate decreased gradually as the concentration of the extract decreased. At $100 \mu \mathrm{g} / \mathrm{mL}$, the DPPH scavenging rate of stilbenoid-rich extract from the Tifrunner cultivar was $90.67 \pm 0.64 \%$. Whereas the rate was $82.94 \pm 0.75 \%$ and $76.80 \pm 1.51 \%$ for Hull and Georgia Green, respectively. Interestingly, the extract from Tifrunner hairy roots had significantly higher $(p<0.05)$ antioxidant capacity at a lower concentration of $6.25 \mu \mathrm{g} / \mathrm{mL}$ and $3.125 \mu \mathrm{g} / \mathrm{mL}$ when compared to stilbenoid-rich extract of the other two cultivars (Figure 6). The DPPH scavenging ability at concentrations of $6.25 \mu \mathrm{g} / \mathrm{mL}$ and $3.125 \mu \mathrm{g} / \mathrm{mL}$ for the extract of Tifrunner were $61.70 \pm 10.74 \%$ and $41.24 \pm 9.12 \%$, for Hull were $42.26 \pm 5.96 \%$ and $26.70 \pm 6.45 \%$, and for Georgia Green were $37.20 \pm 13.41 \%$ and $23.15 \pm 7.98 \%$ respectively. The DPPH scavenging rate of stilbenoid-rich extracts from all three cultivars was lowest at $0.78125 \mu \mathrm{g} / \mathrm{mL}$.

The Tifrunner extract had the highest amount of prenylated stilbenoids such as arachidin-1 (207.5 $\pm 7.35 \mu \mathrm{g} / \mathrm{mg})$, arachidin-2 $(39.15 \pm 0.98 \mu \mathrm{g} / \mathrm{mg})$, arachidin-3 $(75.28 \pm 7.39 \mu \mathrm{g} / \mathrm{mg})$, and arachidin-5 $(30.92 \pm 1.52 \mu \mathrm{g} / \mathrm{mg})$ in terms of dry weight of the extract whereas Hull extract had highest amount of resveratrol $(60.56 \pm 1.19 \mu \mathrm{g} / \mathrm{mg})$ (Table 2). The higher DPPH scavenging rate for Tifrunner stilbenoid-rich extract might correlate to a higher amount of prenylated stilbenoids present in the extract as compared to the other two cultivars. Overall, Tifrunner stilbenoid-rich extract had the highest DPPH scavenging rate followed by Hull and then Georgia Green extract. 


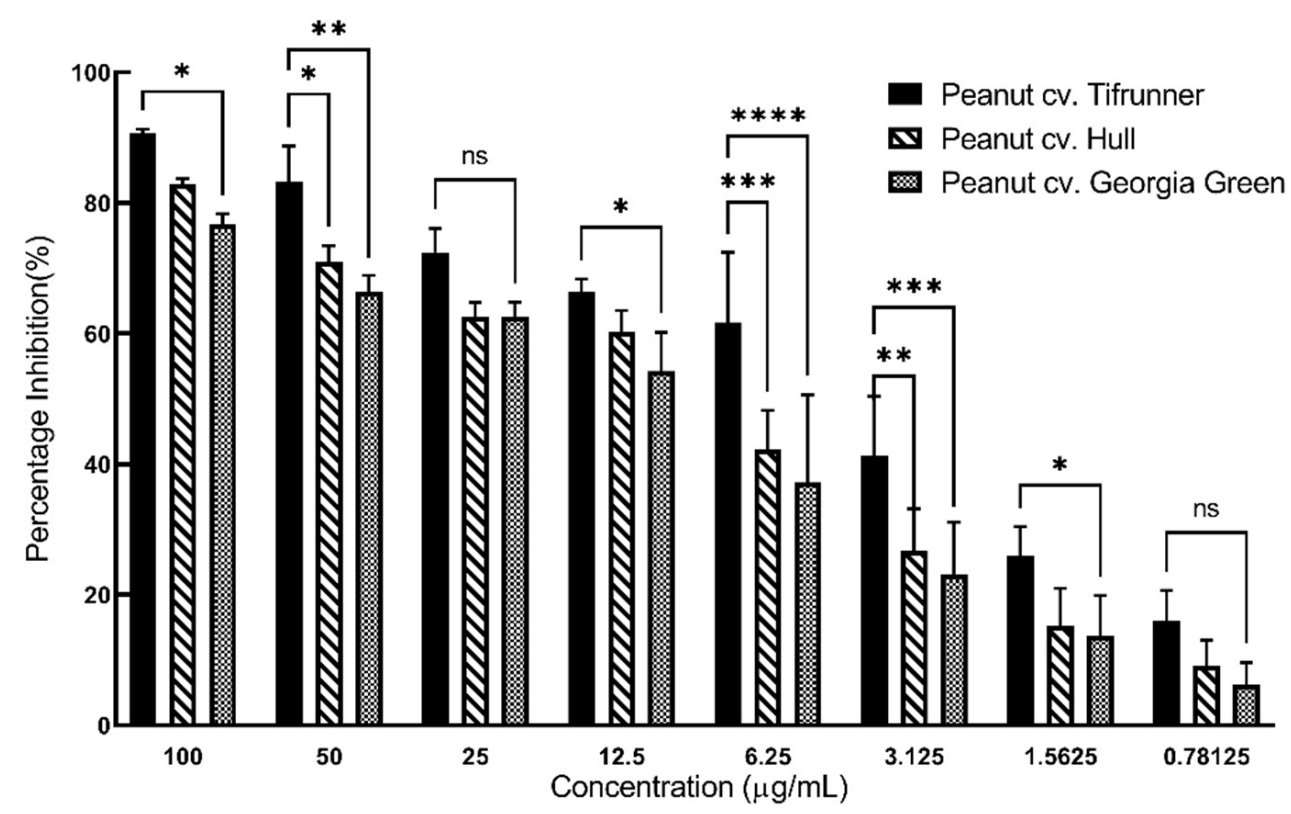

Figure 6. Comparison of total antioxidant capacity of medium extracts from hairy root cultures of peanut cultivars Tifrunner, Hull (line 3), and Georgia Green at different concentrations. Antioxidant capacity was evaluated by the DPPH assay method. Values are the average of three independent experiments, each performed in technical triplicate. Error bar represents standard deviation. Statistical analysis was performed with two-way ANOVA with Tukey's multiple-comparisons test. The asterisks above the connecting line represent a significant difference when compared to the total antioxidant activity among three cultivars ${ }^{*}, p<0.033 ;{ }^{* *}, p<0.002 ; * * *, p<0.001 ; * * * *, p<0.0001$; ns, not significant).

Table 2. Amount of stilbenoid per dry weight of the extract $(\mu \mathrm{g} / \mathrm{mg})$ in three different cultivars of peanuts.

\begin{tabular}{cccc}
\hline \multirow{2}{*}{ Stilbenoids } & \multicolumn{3}{c}{$\mu \mathbf{g} / \mathbf{m g ~ D W}^{\mathbf{a}}$} \\
\cline { 2 - 4 } & Tifrunner & Hull & Georgia Green \\
\hline Resveratrol & $29.47 \pm 1.40$ & $60.56 \pm 1.19$ & $12.52 \pm 0.29$ \\
Arachidin-5 & $30.92 \pm 1.52$ & $13.5 \pm 0.29$ & $6.9 \pm 0.13$ \\
Arachidin-1 & $207.5 \pm 7.35$ & $162.37 \pm 1.33$ & $108.76 \pm 1.53$ \\
Arachidin-2 & $39.15 \pm 0.98$ & $28.21 \pm 1.97$ & $19.74 \pm 2.21$ \\
Arachidin-3 & $75.28 \pm 7.39$ & $72.24 \pm 2.05$ & $46.78 \pm 0.52$ \\
\hline
\end{tabular}

a Data are the means \pm SD of the experiments performed in technical triplicate.

Based on the DPPH antioxidant assay, the $\mathrm{IC}_{50}$ value for the stilbenoid-rich extract from all three extracts was calculated (Figure 7). The $\mathrm{IC}_{50}$ value for the stilbenoid-rich extract from the Tifrunner cultivar was $6.004 \mu \mathrm{g} / \mathrm{mL}$, from the Hull cultivar was $8.147 \mu \mathrm{g} / \mathrm{mL}$ and from Georgia Green was $7.768 \mu \mathrm{g} / \mathrm{mL}$ respectively. The $\mathrm{IC}_{50}$ value represents the amount of stilbenoid-rich extract required to decrease the initial concentration of DPPH by $50 \%$. The lowest $\mathrm{IC}_{50}$ value was found for the stilbenoid-rich extract from Tifrunner hairy roots suggesting that the extract had higher radical scavenging activity as compared to extract from the other two cultivars. Thus, stilbenoid-rich extract from Tifrunner hairy root had higher antioxidant activity followed by Georgia Green and Hull in terms of $\mathrm{IC}_{50}$ value.

Previously, the ethanolic extract of peanut sprouts rich in stilbenoids, such as resveratrol, arachidin-1, and arachidin-3, showed antioxidant and anti-inflammatory activities [23]. The antioxidant activity of stilbenoid-rich extract have been previously reported from peanut hairy roots treated with paraquat, MeJA, and $C D$ and peanut hairy roots treated with cadmium, MeJA, and CD $[24,25]$. In this study, the $\mathrm{IC}_{50}$ value of the stilbenoid-rich extract of peanut hairy roots was lower in comparison to the phenolic extract of grape 
pomace from five different red grape cultivars with $\mathrm{IC}_{50}$ values ranging from $14.45 \mu \mathrm{g} / \mathrm{mL}$ to $38.93 \mu \mathrm{g} / \mathrm{mL}$ suggesting higher antioxidant properties of peanut hairy root extracts [26].
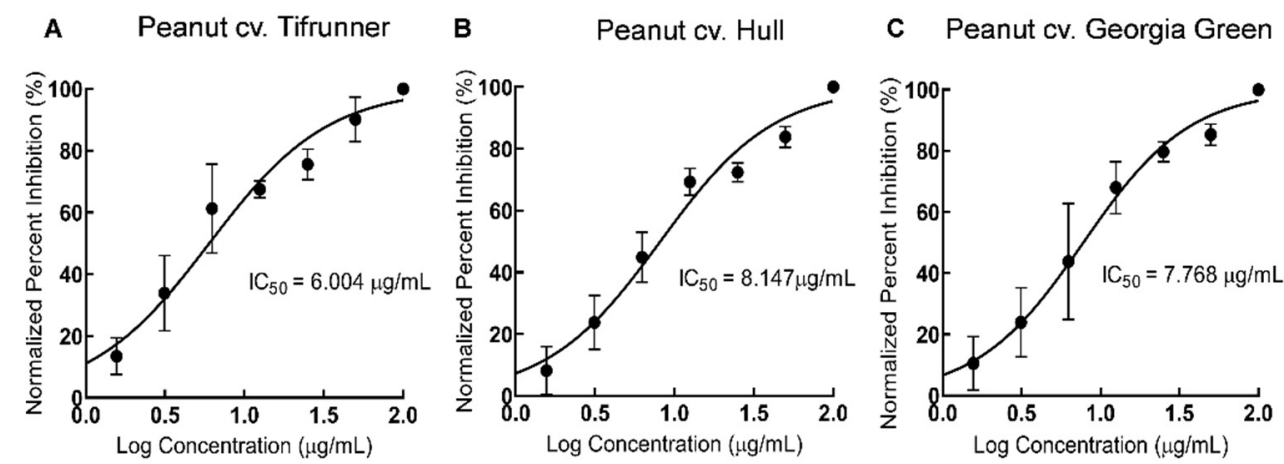

Figure 7. Concentration-dependent inhibitory effect of culture medium extracts from hairy root cultures of peanut cultivars. Tifrunner (A), Hull (B) (line 3), and Georgia Green (C) on DPPH based antioxidant assay. Data are represented as mean \pm SD of three independent experiments, each performed in technical triplicate.

The in vivo study of bio-elicited peanut sprout powder rich in stilbene compounds such as resveratrol, arachidin-1, arachidin-3, and isopentadienylresveratrol suggested that the extract inhibits testosterone-mediated benign prostatic enlargement [27]. Similarly, in vivo study of peanut sprout extracts rich in resveratrol and its glycosides have been reported to have anti-obesity properties [28]. The stilbenoid-rich extracts from elicited peanut hairy root cultures could be further studied to explore their role as functional antioxidant ingredients using in vivo models.

\section{Materials and Methods}

\subsection{Seed Sterilization and Germination of Peanut cv. Tifrunner}

Seeds of peanut cv. Tifrunner (accession No. PI 644011, USDA) were obtained from USDA-ARS Plant Genetic Resources Conservation Unit (Griffin, GA, USA). The shells of the seeds were removed, and then the seeds were surface sterilized by soaking in $0.1 \%$ Palmolive detergent for $2 \mathrm{~min}$ followed by vigorous shaking in $50 \%$ Clorox solution for $15 \mathrm{~min}$ and rinsed using sterilized distilled water 4-5 times. The seeds were placed on plates containing modified Murashige and Skoog medium (MSV) medium with 3\% sucrose and $0.4 \%$ phytagel and cultured under dark conditions until germination. After germination, the plates were transferred to the photoperiod incubator ( $16 \mathrm{hlight} / 8 \mathrm{~h}$ dark) until the emergence of true leaves [17]. Next, the peanut seedlings were transferred to Phytatray ${ }^{\mathrm{TM}}$ boxes (Millipore Sigma, Saint Louis, MO, USA) and kept in the photoperiod incubator for further growth. All cultures were done at $24^{\circ} \mathrm{C}$.

\subsection{Establishment of Hairy Root Cultures of Peanut cv. Tifrunner}

Leaves from the in vitro seedlings were excised and wounded with a scalpel containing Agrobacterium rhizogenes strain ATCC 15834. The wounded leaves were cultured on MSV medium and incubated for a week (till Agrobacterium growth was observed on the leaves). The leaves were then transferred to MSV medium with $250 \mathrm{mg} / \mathrm{L}$ cefotaxime and maintained in this medium until hairy roots were developed. Among several hairy root lines established, line 1 was selected for its sustained and vigorous growth. Molecular analyses were done to confirm hairy root establishment. Genomic DNA was extracted from these roots and PCR analyses were performed for rolC, aux1, and virD2 genes as described before [29]. To establish hairy root cultures, ten 2-3 cm long tips were excised and cultured in $250 \mathrm{~mL}$ flasks containing $50 \mathrm{~mL}$ of MSV medium with $3 \%$ sucrose. The flasks were incubated in an orbital shaker incubator (Innova 44R, New Brunswick Scientific, Hauppauge, NY, USA) at $90 \mathrm{rpm}$ and $28{ }^{\circ} \mathrm{C}$ under continuous darkness. 


\subsection{Growth Conditions and Elicitation of Peanut Hairy Root Cultures of cos. Tifrunner, Hull, and Georgia Green}

Hairy roots of peanut cvs. Hull and Georgia Green were established previously and maintained in $250 \mathrm{~mL}$ media flasks with $50 \mathrm{~mL}$ of MSV medium [17,30]. The hairy root cultures were grown till the mid-log stage prior to elicitation $[17,30]$. The spent medium was discarded and replaced with $100 \mathrm{~mL}$ of MSV medium containing 3\% sucrose with $125 \mu \mathrm{M}$ methyl jasmonate (MeJA), $18 \mathrm{~g} / \mathrm{L}$ cyclodextrin (CD), $3 \mathrm{mM}$ hydrogen peroxide $\left(\mathrm{H}_{2} \mathrm{O}_{2}\right)$, and $1 \mathrm{mM}$ magnesium chloride $\left(\mathrm{MgCl}_{2}\right)$ as described before [18]. All elicitation was carried out under continuous darkness at $28^{\circ} \mathrm{C}$ for $168 \mathrm{~h}$.

\subsection{Extraction and Analysis of Stilbenoids}

For each of the 3 cultivars, i.e., Tifrunner, Hull, and Georgia Green, the 168 h-elicited medium of nine flasks were combined before extraction. The extraction was performed by partitioning the elicited medium with ethyl acetate twice at a ratio of 1:1 first time and 2:1 second time in a separatory funnel by mixing them by vigorous shaking. The obtained organic upper phase was transferred to a round bottom flask and dried using a rotary evaporator (Büchi, rotavapor R-2000, Flawil, Switzerland). The extract was dissolved in $10 \mathrm{~mL}$ methanol. An aliquot of the extract was diluted and analyzed by HPLC. The recovery of each stilbenoid from the elicited medium of the combined nine flasks using ethyl acetate ranged from $79 \%$ to $83 \%$.

Quantitative analysis of stilbenoids was performed using HPLC as described before [31]. Briefly, the chromatography was done in a Sunfire ${ }^{\mathrm{TM}} \mathrm{C} 18,5 \mu \mathrm{m}, 4.6 \times 250 \mathrm{~mm}$ column (Waters, Milford, MA, USA) at $40{ }^{\circ} \mathrm{C}$ and a flow rate at $1.0 \mathrm{~mL} / \mathrm{min}$. The HPLC system was controlled by Chromeleon software (Thermo Scientific, Waltham, MA, USA). The mobile phase consisted of methanol (A) and $0.5 \%$ formic acid (B). The column was initially calibrated with B for $1 \mathrm{~min}$. Then a linear gradient was performed from $60 \% \mathrm{~A}$ to $65 \% \mathrm{~A}$ for $1-20 \mathrm{~min}, 65 \% \mathrm{~A}$ and $35 \% \mathrm{~B}$ to $100 \%$ B for $20-25 \mathrm{~min}$, and $100 \%$ B for $25-30 \mathrm{~min}$. Calibration curves for reference compounds were established at $\mathrm{A}_{320}$ for resveratrol (Biophysica, $\mathrm{La}$ Jolla, CA, USA) $\left(\mathrm{y}=1.2596 \mathrm{x}+4.9349, \mathrm{R}^{2}=0.999\right.$, limit of quantitatation $(\mathrm{LOQ}): 16.74 \mathrm{mg} / \mathrm{L}$, and limit of detection (LOD): $5.524 \mathrm{mg} / \mathrm{L})$, arachidin-2 $\left(\mathrm{y}=0.7009 \mathrm{x}+1.7334, \mathrm{R}^{2}=0.994\right.$, LOQ: $14.44 \mathrm{mg} / \mathrm{L}$, LOD: $4.76 \mathrm{mg} / \mathrm{L})$, and arachidin-5 $\left(\mathrm{y}=1.041 \mathrm{x}+2.1378, \mathrm{R}^{2}=0.996\right.$, LOQ: $7.15 \mathrm{mg} / \mathrm{L}$, LOD: $2.36 \mathrm{mg} / \mathrm{L})$ and at $\mathrm{A}_{340}$ for arachidin- $1\left(\mathrm{y}=0.748 \mathrm{x}+1.589, \mathrm{R}^{2}=0.997\right.$, LOQ: $5.44 \mathrm{mg} / \mathrm{L}$, LOD: $1.80 \mathrm{mg} / \mathrm{L})$ and arachidin-3 $\left(0.8464 \mathrm{x}+1.3747, \mathrm{R}^{2}=0.998\right.$, LOQ: $6.52 \mathrm{mg} / \mathrm{L}$, LOD: $2.15 \mathrm{mg} / \mathrm{L}$ ). Limit of quantitation (LOQ) and limit of detection (LOD) were determined as described before [32]. Production of arachidin reference standards was described previously [33].

Liquid chromatography-mass spectrometry qualitative analysis of stilbenoids was done using an UltiMate 3000 rapid separation LC system (Thermo Scientific, Waltham, MA, USA). The separation method was similar to the HPLC conditions described above. The LTQ XL linear ion trap mass spectrophotometer (Thermo Scientific, Waltham, MA, USA) with an electrospray ionization source was used for obtaining structural information of stilbenoids following the method described previously [34]. Briefly, all mass spectra were performed in positive and negative modes with ion spray voltage at $4 \mathrm{kV}$, sheath gas at 45 arbitrary units and capillary temperature at $300{ }^{\circ} \mathrm{C}$. Full scans were recorded in the mass range $m / z 50$ to 2000. The collision energy of 35\% was applied in collision-induced dissociation. The data was recorded and analyzed by Xcalibur software (Thermo Scientific, Waltham, MA, USA).

\subsection{DPPH Antioxidant Assay}

A microplate DPPH (2,2-diphenyl-1-picrylhydrazyl) assay was carried out using $200 \mu \mathrm{g} / \mathrm{mL}$ culture medium extract of peanut hairy roots cvs. Tifrunner, Hull, and Georgia Green using a protocol established by Patrick Roberto in the Medina-Bolivar laboratory [35]. First, $200 \mu \mathrm{L}$ of $200 \mu \mathrm{g} / \mathrm{mL}$ of extract was added to three separate wells on row A of the 96 well plates followed by the addition of $100 \mu \mathrm{L}$ of methanol to the first three wells 
of rows B-H of the 96 well plates. The $100 \mu \mathrm{L}$ sample in row A was transferred from row $A$ to row $B$, row $B$ to row $C$ and the process was repeated until the very last row. Finally, $100 \mu \mathrm{L}$ of $100 \mu \mathrm{M}$ DPPH was added to all the wells with samples on the 96 well plate. The control was a mixture of $100 \mu \mathrm{L}$ of methanol and $100 \mu \mathrm{L}$ of $100 \mu \mathrm{M}$ DPPH and the blank contained $100 \mu \mathrm{L}$ methanol. The reaction mixture was incubated in dark at room temperature for $30 \mathrm{~min}$. Finally, the absorbance was measured after exactly $30 \mathrm{~min}$ at $515 \mathrm{~nm}$ on a BioTek absorbance microplate well reader using the Gen5 data analysis software [36]. The percentage inhibition was calculated using the formula below:

$$
\text { Percent scavenging }=1-\left(\frac{\text { Abs (sample })- \text { Abs (blank) }}{\text { Abs (control) }- \text { Abs (blank) }}\right)
$$

The data were fit into sigmoidal dose-response inhibition curves with non-linear regression and $\mathrm{IC}_{50}$ values were calculated in GraphPad Prism version 9.10 software (San Diego, CA, USA).

\subsection{Purification and Identification of Arachidin-6 in Peanut Hairy Root Culture}

For purification of arachidin-6, $900 \mathrm{~mL}$ of elicited medium was obtained from a pool of about 9 flasks of $168 \mathrm{~h}$ elicited peanut $\mathrm{cv}$. Tifrunner hairy root culture. The medium was partitioned with an equal volume of ethyl acetate twice in a 2-L separatory funnel. The organic phase was recovered and dried in rotavapor (Buchi, Flawil, Switzerland), and the crude extract (approximately $1.14 \mathrm{~g}$ ) was further used for semi-preparative HPLC.

For semi-preparative HPLC, a Sunfire ${ }^{\circledR}$ C18 OBD ${ }^{\mathrm{TM}}$ Prep, $10 \times 250 \mathrm{~mm}$ column (Waters, Milford, MA, USA) at $40{ }^{\circ} \mathrm{C}$ and a flow rate at $4.0 \mathrm{~mL} / \mathrm{min}$ were used. The HPLC system was controlled by Chromeleon software (Thermofisher). The mobile phase consisted of methanol (A) and $0.5 \%$ formic acid (B). The mobile phase consisted of methanol (A) and $0.5 \%$ formic acid (B). A linear gradient started from $40 \%$ A to $50 \%$ A for $2 \mathrm{~min}$, then from $50 \%$ A to $70 \%$ A for $2-50 \mathrm{~min}$, and $100 \%$ A for $50-55 \mathrm{~min}$. Based on retention time and UV, arachidin-6 peak was collected and dried under nitrogen gas for subsequent MS analysis as described above.

\subsection{Statistical Analysis}

Two-way ANOVA with Tukey's multiple-comparison tests was performed for data in Figures 5 and 6 with GraphPad Prism 9 software, version 9.10.

\section{Conclusions}

In conclusion, the antioxidant activity of stilbenoid-rich extracts obtained from elicited hairy roots of three cultivars of peanut was compared. The extract from cv. Tifrunner had significantly higher radical scavenging activity even at lower concentrations when compared to extracts of the other two cultivars. The higher antioxidant activity in Tifrunner stilbenoid-rich extract suggested that there might be a correlation between the level of stilbenoids and antioxidant properties in the hairy root extract. The hairy root of wholegenome sequenced peanut cv. Tifrunner was established and characterized for the first time and may provide a potential platform for further elucidation of the biosynthetic pathway of these prenylated stilbenoids. The antioxidant stilbenoid-rich extract from peanut could be further studied for its potential implication as nutraceuticals for promoting human health.

Supplementary Materials: The following are available online, Figure S1: PCR analysis of Tifrunner hairy root line 1 with primers targeting the rolC, aux1, and virD2 genes. Plasmid pRi15834 was used as positive control and $\mathrm{ddH} 2 \mathrm{O}$ was used as negative control. Figure S2: Purification of arachidin-6. (A) semi-preparative HPLC profile of ethyl acetate extract of peanut cv. Tifrunner (B) HPLC profile of purified arachidin-6. Figure S3: UV spectrum of arachidin-6. Figure S4: MS ion chromatogram of arachidin-6 under negative mode. Figure S5: MS ion chromatogram of arachidin-6 under positive mode. 
Author Contributions: Conceptualization, G.G. and F.M.-B.; methodology, G.G., R.H. and F.M.-B.; formal analysis, G.G. and F.M.-B.; investigation, G.G., R.H. and F.M.-B.; resources, F.M.-B.; writingoriginal draft preparation, G.G.; writing—review and editing, F.M.-B.; visualization, G.G. and F.M.-B.; supervision, F.M.-B.; project administration, F.M.-B.; funding acquisition, F.M.-B. All authors have read and agreed to the published version of the manuscript.

Funding: This research was funded by the Arkansas Biosciences Institute (Fund No. 200156).

Institutional Review Board Statement: Not applicable.

Informed Consent Statement: Not applicable.

Data Availability Statement: The data of this study are available upon request.

Conflicts of Interest: The authors declare no competing financial interest.

Sample Availability: Not available.

\section{References}

1. Apel, K.; Hirt, H. Reactive oxygen species: Metabolism, oxidative stress, and signal transduction. Annu. Rev. Plant Biol. 2004, 55, 373-379. [CrossRef]

2. Gulcin, İ. Antioxidants and antioxidant methods: An updated overview. Arch. Toxicol. 2020, 94, 651-715. [CrossRef]

3. Tang, S.Y.; Whiteman, M.; Peng, Z.F.; Jenner, A.; Yong, E.L.; Halliwell, B. Characterization of antioxidant and antiglycation properties and isolation of active ingredients from traditional chinese medicines. Free Radic. Biol. Med. 2004, 36, 1575-1587. [CrossRef]

4. Halliwell, B.; Murcia, M.A.; Chirico, S.; Aruoma, O.I. Free radicals and antioxidants in food and in vivo: What they do and how they work. Crit. Rev. Food Sci. Nutr. 1995, 35, 7-20. [CrossRef]

5. Dávid, C.Z.; Hohmann, J.; Vasas, A. Chemistry and pharmacology of Cyperaceae stilbenoids: A Review. Molecules 2021, $26,2794$. [CrossRef]

6. Sobolev, V.S. Localized production of phytoalexins by peanut (Arachis hypogaea) kernels in response to invasion by Aspergillus species. J. Agric. Food Chem. 2008, 56, 1949-1954. [CrossRef]

7. Sobolev, V.S. Production of phytoalexins in peanut (Arachis hypogaea) seed elicited by selected microorganisms. J. Agric. Food Chem. 2013, 61, 1850-1858. [CrossRef]

8. Sobolev, V.S.; Khan, S.I.; Tabanca, N.; Wedge, D.E.; Manly, S.P.; Cutler, S.J.; Coy, M.R.; Becnel, J.J.; Neff, S.A.; Gloer, J.B. Biological activity of peanut (Arachis hypogaea) phytoalexins and selected natural and synthetic stilbenoids. J. Agric. Food Chem. 2011, 59, 1673-1682. [CrossRef]

9. Sobolev, V.S.; Potter, T.L.; Horn, B.W. Prenylated stilbenes from peanut root mucilage. Phytochem. Anal. 2006, 17, 312-322. [CrossRef] [PubMed]

10. Wu, Z.; Song, L.; Huang, D. Food grade fungal stress on germinating peanut seeds induced phytoalexins and enhanced polyphenolic antioxidants. J. Agric. Food Chem. 2011, 59, 5993-6003. [CrossRef]

11. Yang, T.; Fang, L.; Sanders, S.; Jayanthi, S.; Rajan, G.; Podicheti, R.; Thallapuranam, S.K.; Mockaitis, K.; Medina-Bolivar, F. Stilbenoid prenyltransferases define key steps in the diversification of peanut phytoalexins. J. Biol. Chem. 2018, $293,28-46$. [CrossRef]

12. Yang, T.; Fang, L.; Medina-Bolivar, F. Production and biosynthesis of bioactive stilbenoids in hairy root cultures. In Production of Plant Derived Natural Compounds through Hairy Root Culture; Malik, S., Ed.; Springer International Publishing: Cham, Switzerland, 2017; pp. 45-64.

13. Brents, L.; Medina-Bolivar, F.; Seely, K.; Nair, V.; Bratton, S.; Nopo-Olazabal, L.; Patel, R.; Liu, H.; Doerksen, R.; Prather, P.; et al. Natural prenylated resveratrol analogs arachidin-1 and -3 demonstrate improved glucuronidation profiles and have affinity for cannabinoid receptors. Xenobiotica 2011, 42, 139-156. [CrossRef]

14. Chang, J.-C.; Lai, Y.-H.; Djoko, B.; Wu, P.-L.; Liu, C.-D.; Liu, Y.-W.; Chiou, R.Y.-Y. Biosynthesis enhancement and antioxidant and anti-inflammatory activities of peanut (Arachis hypogaea L.) arachidin-1, arachidin-3, and isopentadienylresveratrol. J. Agric. Food Chem. 2006, 54, 10281-10287. [CrossRef] [PubMed]

15. Huang, C.-P.; Au, L.-C.; Chiou, R.Y.-Y.; Chung, P.-C.; Chen, S.-Y.; Tang, W.-C.; Chang, C.-L.; Fang, W.-H.; Lin, S.-B. Arachidin-1, a peanut stilbenoid, induces programmed cell death in human leukemia HL-60 cells. J. Agric. Food Chem. 2010, 58, 12123-12129. [CrossRef]

16. Zhang, L.; Ravipati, A.S.; Koyyalamudi, S.R.; Jeong, S.C.; Reddy, N.; Smith, P.T.; Bartlett, J.; Shanmugam, K.; Münch, G.; Wu, M.J. Antioxidant and anti-inflammatory activities of selected medicinal plants containing phenolic and flavonoid Compounds. J. Agric. Food Chem. 2011, 59, 12361-12367. [CrossRef]

17. Condori, J.; Sivakumar, G.; Hubstenberger, J.; Dolan, M.C.; Sobolev, V.S.; Medina-Bolivar, F. Induced biosynthesis of resveratrol and the prenylated stilbenoids arachidin- 1 and arachidin- 3 in hairy root cultures of peanut: Effects of culture medium and growth stage. Plant Physiol. Biochem. 2010, 48, 310-318. [CrossRef] 
18. Fang, L.; Yang, T.; Medina-Bolivar, F. Production of prenylated stilbenoids in hairy root cultures of peanut (Arachis hypogaea) and its wild relatives $A$. ipaensis and A. duranensis via an optimized elicitation procedure. Molecules 2020, 25, 509. [CrossRef]

19. Chayjarung, P.; Poonsap, W.; Pankaew, C.; Inmano, O.; Kongbangkerd, A.; Limmongkon, A. Using a combination of chitosan, methyl jasmonate, and cyclodextrin as an effective elicitation strategy for prenylated stilbene compound production in Arachis hypogaea L. hairy root culture and their impact on genomic DNA. Plant Cell Tissue Organ Cult. 2021, 147, 117-129. [CrossRef]

20. Agarwal, G.; Clevenger, J.; Pandey, M.K.; Wang, H.; Shasidhar, Y.; Chu, Y.; Fountain, J.C.; Choudhary, D.; Culbreath, A.K.; Liu, X.; et al. High-density genetic map using whole-genome resequencing for fine mapping and candidate gene discovery for disease resistance in peanut. Plant Biotechnol. J. 2018, 16, 1954-1967. [CrossRef] [PubMed]

21. de Bruijn, W.J.C.; Araya-Cloutier, C.; Bijlsma, J.; de Swart, A.; Sanders, M.G.; de Waard, P.; Gruppen, H.; Vincken, J.-P. Antibacterial prenylated stilbenoids from peanut (Arachis hypogaea). Phytochem. Lett. 2018, 28, 13-18. [CrossRef]

22. Moon, J.-K.; Shibamoto, T. Antioxidant assays for plant and food components. J. Agric. Food Chem. 2009, 57, 1655-1666. [CrossRef] [PubMed]

23. Limmongkon, A.; Nopprang, P.; Chaikeandee, P.; Somboon, T.; Wongshaya, P.; Pilaisangsuree, V. LC-MS/MS profiles and interrelationships between the anti-inflammatory activity, total phenolic content and antioxidant potential of Kalasin 2 cultivar peanut sprout crude extract. Food Chem. 2018, 239, 569-578. [CrossRef] [PubMed]

24. Pilaisangsuree, V.; Anuwan, P.; Supdensong, K.; Lumpa, P.; Kongbangkerd, A.; Limmongkon, A. Enhancement of adaptive response in peanut hairy root by exogenous signalling molecules under cadmium stress. J. Plant Physiol. 2020, $254,153278$. [CrossRef] [PubMed]

25. Wongshaya, P.; Chayjarung, P.; Tothong, C.; Pilaisangsuree, V.; Somboon, T.; Kongbangkerd, A.; Limmongkon, A. Effect of light and mechanical stress in combination with chemical elicitors on the production of stilbene compounds and defensive responses in peanut hairy root culture. Plant Physiol. Biochem. 2020, 157, 93-104. [CrossRef] [PubMed]

26. Ruberto, G.; Renda, A.; Daquino, C.; Amico, V.; Spatafora, C.; Tringali, C.; Tommasi, N.D. Polyphenol constituents and antioxidant activity of grape pomace extracts from five Sicilian red grape cultivars. Food Chem. 2007, 100, 203-210. [CrossRef]

27. Cheng, P.; Chiu, P.; Chang, J.; Lin, S.; Li, Y.; Lo, D.; Lai, L.; Wu, S.; Chiou, R. Inhibition of testosterone-mediated benign prostatic enlargement of orchiectomized Sprague-Dawley rats by diets supplemented with bio-elicited peanut sprout powder (BPSP) and three new BPSP-extracted natural compounds identified. J. Funct. Foods 2021, 79, 104383. [CrossRef]

28. Kim, S.; Seo, J.; Kim, B.; Kim, H.; Lee, H.; Kim, J. Anti-obesity activity of peanut sprout extract. Food Sci. Biotechnol. 2014, 23, 601-607. [CrossRef]

29. Medina-Bolivar, F.; Condori, J.; Rimando, A.M.; Hubstenberger, J.; Shelton, K.; O’Keefe, S.F.; Bennett, S.; Dolan, M.C. Production and secretion of resveratrol in hairy root cultures of peanut. Phytochemistry 2007, 68, 1992-2003. [CrossRef]

30. Balmaceda, C. Efecto de la Cicodextrina y el Metil Jamonato en la Producción de Resveratrol y sus Análogos Prenilados Araquidina-1 y Araquidina-3 Empleando Raices en Cabellera de Mani. Licentiate Thesis, Universidad Peruana Cayetano Heredia, Lima, Peru, 2011.

31. Yang, T.; Fang, L.; Nopo-Olazabal, C.; Condori, J.; Nopo-Olazabal, L.; Balmaceda, C.; Medina-Bolivar, F. Enhanced production of resveratrol, piceatannol, arachidin-1, and arachidin-3 in hairy root cultures of peanut co-treated with methyl jasmonate and cyclodextrin. J. Agric. Food Chem. 2015, 63, 3942-3950. [CrossRef]

32. Shrivastava, A. Methods for the determination of limit of detection and limit of quantitation of the analytical methods. Chron. Young Sci. 2011, 2, 21-25. [CrossRef]

33. Ball, J.M.; Medina-Bolivar, F.; Defrates, K.; Hambleton, E.; Hurlburt, M.E.; Fang, L.; Yang, T.; Nopo-Olazabal, L.; Atwill, R.L.; Ghai, P.; et al. Investigation of stilbenoids as potential therapeutic agents for rotavirus gastroenteritis. Adv. Virol. 2015, 2015, 293524. [CrossRef] [PubMed]

34. Marsh, Z.; Yang, T.; Nopo-Olazabal, L.; Wu, S.; Ingle, T.; Joshee, N.; Medina-Bolivar, F. Effect of light, methyl jasmonate and cyclodextrin on production of phenolic compounds in hairy root cultures of Scutellaria lateriflora. Phytochemistry 2014, 107, 50-60. [CrossRef] [PubMed]

35. Roberto, P. Antioxidant Characterization of Peanut Hairy Roots Extracts Enriched with Prenylated Stilbenoids. Master's Thesis, Arkansas State University, Jonesboro, AR, USA, 2020.

36. Sharma, O.P.; Bhat, T.K. DPPH antioxidant assay revisited. Food Chem. 2009, 113, 1202-1205. [CrossRef] 